\title{
Increased Damage to Type II Collagen in Osteoarthritic Articular Cartilage Detected by a New Immunoassay
}

\author{
Anthony P. Hollander, * Terrence F. Heathfield, * Carolyn Webber, * Yukiko Iwata, * \\ Robert Bourne, ${ }^{\star}$ Cecil Rorabeck, ${ }^{\star}$ and A. Robin Poole* \\ *Joint Diseases Laboratory, Shriners Hospital for Crippled Children and Division of Surgical Research, Department of Surgery, McGill \\ University, Montreal, Quebec, H3G 1 A6 Canada; and ${ }^{\ddagger}$ Division of Orthopaedics, Department of Surgery, University of Western Ontario, \\ London, Ontario, N6A 5 A5 Canada
}

\begin{abstract}
A new immunoassay was developed to detect denaturation of type II collagen in osteoarthritis (OA). A peptide, $\alpha 1$ (II)CB11B, located in the CB11 peptide of type II collagen, was synthesized and used to produce a monoclonal antibody (COL2-3/4m) of the $\operatorname{IgG}_{1}(\kappa)$ isotype. This reacts with a defined epitope in denatured but not native type II collagen and the $\alpha 3$ chain of type XI collagen. The latter is present in very small amounts (about $1 \% \mathrm{wt} / \mathrm{wt}$ ) in cartilage relative to the $\alpha 1$ (II) chain. By using an enzyme-linked immunosorbent assay, type II collagen denaturation and total type II collagen content were determined. The epitope recognized by the antibody was resistant to cleavage by $\alpha$-chymotrypsin and proteinase $K$ which were used to extract $\alpha 1$ (II)-CB11B from the denatured ( $\alpha$-chymotrypsin soluble) and residual native (proteinase $\mathrm{K}$ soluble) collagen $\alpha$-chains, respectively, present in human femoral articular cartilage. Type II collagen content was significantly reduced from a mean (range) of $14 \%(9.2-20.8 \%)$ of wet weight in 8 normal cartilages to $10.3 \%(7.4-15.0 \%)$ in $16 \mathrm{OA}$ cartilages. This decrease, which may result in part from an increased hydration, was accompanied by an increase in the percent denaturation of type II collagen in OA to $6.0 \%$ of total type II collagen compared with $1.1 \%$ in normal tissue. The percent denaturation was ordinarily greater in the more superficial zone than in the deep zone of OA cartilage. ( $J$. Clin. Invest. 1994. 93:1722-1732.) Key words: arthritis • cartilage $\bullet$ collagen II $\cdot$ collagenase $\cdot$ degradation
\end{abstract}

\section{Introduction}

Type II collagen and aggrecan (a large, aggregating proteoglycan) are the two major components of the extracellular matrix of cartilage. The collagen, which is present in a fibrillar form, provides tensile strength whereas the aggrecan is responsible for

Dr. Hollander's present address is Department of Human Metabolism and Clinical Biochemistry, University of Sheffield Medical School, Beech Hill Road, Sheffield S10 2RX, UK.

Address correspondence to Dr. A. R. Poole, Joint Diseases Laboratory, Shriners Hospital for Crippled Children, 1529 Cedar Avenue, Montreal, Quebec H3G 1A6, Canada.

Received for publication 10 August 1993 and in revised form 10 December 1993.

J. Clin. Invest.

(C) The American Society for Clinical Investigation, Inc.

$0021-9738 / 94 / 04 / 1722 / 11 \$ 2.00$

Volume 93, April 1994, 1722-1732 compressive stiffness of cartilage (1-3). Degradation and loss from the matrix of either of these molecules could contribute significantly to destruction of articular cartilage and loss of its function in patients with arthritic diseases. The proteolytic degradation of proteoglycan has been widely studied (3-6). In contrast, there have been very few studies of type II collagen degradation, owing to a lack of adequate methodology with which to detect damage to specific collagen molecules and their release. Electron microscopic studies have revealed damage to collagen fibrils in articular cartilage in RA (7). Damage to collagen at the junction of cartilage with pannus (8) and at the articular surface (9) has also been noted in RA. In osteoarthritis (OA), ${ }^{1}$ Venn and Maroudas (10) used estimations of hydroxyproline to demonstrate a decrease in the collagen content as a percentage of wet weight of femoral head cartilage compared with normal (postmortem) cartilage. Such analyses cannot distinguish different types of collagen in the cartilage.

Specific studies of damage to type II collagen resulting in denaturation (unwinding) of the triple helix were first made by Dodge and Poole (11) and Dodge et al. (12), who showed that a polyclonal rabbit antiserum raised against cyanogen bromide peptides of type II collagen will react specifically with denatured, but not native (triple helical), type II collagen $\alpha$ chains or fragments thereof containing the recognized epitopes. The antiserum was used to demonstrate, by immunolocalization and immunochemical analysis of cartilage extracts, type II collagen cleavage in situ in OA and RA and type II collagen denaturation induced when cartilage is cultured with interleukin-1. These studies clearly demonstrated that arthritic cartilages exhibit increased staining for type II collagen denaturation. Moreover, whereas in aging and OA damage was first observed at and close to the articular surface, in RA early damage was usually most pronounced around chondrocytes in the deep zone, adjacent to subchondral bone $(11,12)$. This revealed that there are differences in the sites of cleavage of type II collagen that may be due to differences in the pathogenesis of these diseases (see also reference 3 for a discussion). The fact that early damage to type II collagen is predominantly pericellular/ territorial suggests that in the majority of cases collagen damage was mediated by the chondrocyte. Subsequently we showed, with a specific, nontoxic hydroxamate inhibitor, that cleavage of type II collagen in human articular cartilage is mediated by metalloproteinases released from chondrocytes (13). Other immunochemical studies with the antiserum revealed that the metalloproteinase collagenase may in part be responsi-

1. Abbreviations used in this paper: HDC, heat-denatured type II collagen; OA, osteoarthritis; TPCK, $N$-tosyl-L-phenylalanine chloromethyl ketone. 
ble for this denaturation. This is the only mammalian proteinase that can cleave the triple helix of this molecule (4).

At that time it was not possible to quantitate collagen denaturation by immunoassay. Moreover, because we showed that denatured collagen is retained in the fibril and not released ( 11 , 12 ), it was necessary to develop a means of selectively extracting denatured type II collagen so that it could be measured. In order to assay collagen fragments and conduct other specific immunological studies, it is preferable to determine the content of just one epitope, of known location within the collagen molecule, by using a single monoclonal antibody in an immunoassay. Under these circumstances any one fragment will react either fully or not at all in the assay and so the quantity of denatured collagen and identity of such fragments containing the defined epitope can be more accurately determined. Furthermore, a protease with gelatinase-like activity that cleaves neither the chosen epitope nor native (helical) collagen could theoretically be used to extract those denatured collagen $\alpha$ chains that are retained in the fibril.

To study damage to type II collagen in articular cartilage in arthritis, we developed an immunoassay based on our earlier immunochemical work $(11,12)$. Here we describe and use this assay to provide the first quantitative evidence for increased damage to type II collagen in situ and decreased content of total type II collagen in OA cartilage.

\section{Methods}

Tissue. Human articular cartilages were removed from the anterior (loaded) region of the femoral condyles of adult knee joints. OA cartilages were obtained at surgery from patients undergoing total joint arthroplasty. Site-matched nonarthritic articular cartilages of normal appearance were obtained at autopsy within $15 \mathrm{~h}$ postmortem from individuals with no known history or signs of arthritic/joint abnormalities. Patient details and Mankin grades of the normal and OA cartilage specimens are shown in Table I. Previously, cartilage from these same sites has been analyzed for the proteoglycan aggrecan (6).

Preparation of cartilage plugs. In that cutting cartilage can produce denaturation of type II collagen, care was taken to prepare defined plugs of cartilage using a specially made, standardized, stainless steel punch. This avoided variable results and the increased denaturation obtained by dicing the cartilage with a scalpel or by preparing frozen sections (data not shown). Wherever possible, a full depth slice of cartilage was taken from each femoral condyle (medial and lateral) and two full-depth cylindrical plugs, each $\sim 4 \mathrm{~mm}$ in diameter by $2 \mathrm{~mm}$ deep, were prepared from each slice using the steel punch. One of the plugs was used for the histological assessment of Mankin grade, as previously described $(6,14)$. This did not include analysis of the calcified cartilage, hence the maximum grade in the group of OA cartilages was only 13. The other plug was used for the extraction and assay of type II collagen. In some experiments the full-depth plugs were approximately divided into an upper and a lower half by using a scalpel. The

Table I. Patient Details

\begin{tabular}{lcccccc}
\hline $\begin{array}{l}\text { Disease } \\
\text { group }\end{array}$ & $n$ & $\begin{array}{c}\text { Mean } \\
\text { age }\end{array}$ & $\begin{array}{c}\text { Age } \\
\text { range }\end{array}$ & Male/female & $\begin{array}{c}\text { Median } \\
\text { Mankin } \\
\text { grade }\end{array}$ & $\begin{array}{c}\text { Range of } \\
\text { Mankin } \\
\text { grades }\end{array}$ \\
\hline & & $y r$ & $y r$ & $\%$ & & \\
Normal & 8 & 56 & $28-81$ & $50: 50$ & 2 & $0-6$ \\
OA & 16 & 69 & $57-84$ & $57: 43$ & 5 & $2-10$ \\
\hline
\end{tabular}

upper $1 \mathrm{~mm}$ included the articular surface and upper-mid zone; the lower $1 \mathrm{~mm}$ consisted of lower-mid and deep zone cartilage. It was essential to standardize the tissue sample preparation in this way because cutting the cartilage causes denaturation of type II collagen.

Identification and synthesis of a type II collagen B-cell epitope. Sites containing putative B cell epitopes within the type II collagen $\alpha$ chains were predicted by the identification of hydrophilic domains in the amino acid sequence, according to the method of Hopp and Woods (15). Only the cyanogen bromide peptide 11 of the $\alpha 1$ (II) chain was analyzed for hydrophobicity/hydrophilicity, because this 279-amino acid peptide resides within the triple helix and has already been shown to be immunogenic in rabbits (11). Additional criteria for selection of a suitable peptide sequence were as follows: $(a)$ The epitope should not include any hydroxylysine residues (these could be involved in crosslink formation and may be substituted with carbohydrate chains that could block antibody-binding). ( $b$ ) The epitope should be well conserved between species (to permit species cross-reactivity). $(c)$ The epitope should have minimal homology with sequences from other proteins and collagen $\alpha$ chains. $(d)$ The epitope should be resistant to hydrolysis by proteinase $\mathrm{K}$ and $\alpha$-chymotrypsin, which were used to extract from cartilage native and denatured collagen respectively.

For the purposes of analysis, it was assumed that all proline and lysine residues in the " $Y$ " position of the Gly-X-Y repeat sequence were hydroxylated. However, the hydroxyl group did not appear to contribute significantly to the hydrophobicity of cyanogen bromide peptide 11 , in that the hydrophobicity/hydrophilicity profile was almost identical when hydroxyproline and hydroxylysine hydropathy values were replaced with those of proline and lysine respectively.

Peptides up to 23 amino acids long containing a centrally located hydrophilic domain, with an amino-terminal cysteine for conjugation to ovalbumin and a carboxy terminal tyrosine (for iodination if required), were synthesized at a $0.25-\mathrm{mmol}$ scale, using standard Fmoc (9-fluorenylmethoxycarbonyl) chemistry, on an model 431A solidphase peptide synthesizer (Applied Biosystems, Inc., Foster City, CA). The crude peptides were purified by reverse-phase chromatography (Prep-10 Aquapore C8 column, Applied Biosystems Inc.) using an acetonitrile gradient in $0.1 \%$ trifluoroacetic acid.

Preparation of a monoclonal antibody. The chosen peptide, $\alpha 1$ (II)CB1 1 B, was conjugated to ovalbumin through its amino-terminal cysteine, using the coupling reagent bromoacetic acid- $N$-hydroxysuccinimide ester (Sigma Chemical Co., St. Louis, MO), as previously described (16). BALB/c mice were immunized five times at 2-wk intervals by i.p. injection with $100 \mu \mathrm{g}$ of the conjugated peptide emulsified with complete (first immunization) or incomplete (subsequent immunizations) Freund's adjuvant. Serum samples from the mice were then tested in an ELISA (see below) for reactivity with both peptide and heat-denatured type II collagen (HDC). Splenocytes from the mouse showing the best serum antibody response were fused to SP2/0 myeloma cells and monoclonal antibodies were prepared using conventional hybridoma technology $(17,18)$. Cloned hybridoma cells that produced antibodies reacting with both HDC and the immunogenic peptide were expanded in vivo as an ascites (18). The antibody isotype was determined using a commercial isotype screening kit (Southern Biotechnology Inc., Birmingham, AL).

Purification of collagens and preparation for analysis. Bovine and human type II collagen and bovine types I and III collagens were prepared by differential salt precipitation, as previously described (11, 19). Culture medium from bovine growth plate hypertrophic chondrocytes, enriched for type $\mathrm{X}$ collagen by differential salt precipitation, was kindly donated by Dr. M. Alini (Joint Diseases Laboratory, Shriners Hospital, Montreal). Bovine type XI collagen was a generous gift from Dr. J. J. Wu and Dr. D. Eyre, Department of Orthopedics, University of Washington, Seattle. HDC was prepared by heating a $1-\mathrm{mg} / \mathrm{ml}$ solution of type II collagen in PBS for $20 \mathrm{~min}$ at $80^{\circ} \mathrm{C}$. Cyanogen bromide peptides of bovine type II collagen were prepared as described previously (11).

Hydroxyproline assay. Some samples were assayed for hydroxyproline using a colorimetric method (20). 
Detection of mouse antibodies to synthetic $\alpha 1(I I)-C B 11 B$ peptide and HDC. The wells of Immulon-2 flat bottomed ELISA plates (Dynatech Laboratories, Inc., Chantilly, VA) were each coated with $2 \mu \mathrm{g}$ of peptide or HDC, in $50 \mu \mathrm{l}$ of $0.1 \mathrm{M}$ carbonate buffer, $\mathrm{pH} 9.2$, by passive adsorption for $24-48 \mathrm{~h}$ at $4^{\circ} \mathrm{C}$. Nonspecific binding wells were incubated with $50 \mu$ l of buffer. The plates were washed three times with PBS containing $0.1 \% \mathrm{vol} / \mathrm{vol}$ Tween-20. Uncoated binding sites were blocked by incubation with $50 \mu \mathrm{l} /$ well of $1 \% \mathrm{wt} / \mathrm{vol}$ BSA in PBS (PBSBSA) for $30 \mathrm{~min}$ at room temperature. The plates were washed once with PBS-Tween and $50 \mu \mathrm{l}$ of diluted mouse serum or hybridoma culture supernatant was added to individual wells. After incubation for 90 min at $37^{\circ} \mathrm{C}$ the plates were washed three times with PBS-Tween and then alkaline phosphatase-conjugated goat anti-mouse IgG, IgM, and IgA (Zymed Laboratories, San Francisco, CA) diluted 1:500 in PBSBSA-Tween was added at $50 \mu \mathrm{l} /$ well. The plates were incubated for 90 min at $37^{\circ} \mathrm{C}$ and then washed three times with PBS-Tween and once with distilled water. Alkaline phosphatase substrate, disodium $p$-nitrophenyl phosphate (Sigma Chemical Co.), was prepared fresh at 0.5 $\mathrm{mg} / \mathrm{ml}$ in $8.9 \mathrm{mM}$ diethanolamine, $0.25 \mathrm{mM} \mathrm{MgCl}_{2}, \mathrm{pH} 9.8$, and $50 \mu \mathrm{l}$ added to each well for $20-30 \mathrm{~min}$ at $37^{\circ} \mathrm{C}$. The absorbance was measured at $405 \mathrm{~nm}$ on a Multiskan plus MKII plate reader (ICN/Flow, Mississuaga, $\mathrm{ON}$ ).

Inhibition ELISA for denatured type II collagen. Linbro 96-well round-bottom microtiter plates (ICN/Flow) were used for preincubations. They were precoated with $100 \mu \mathrm{l} /$ well of PBS-BSA for $30 \mathrm{~min}$ at room temperature and washed once with PBS-Tween. The outermost wells were not used, to minimize the effects of evaporation. There were six nonspecific binding wells on each plate, which contained $100 \mu \mathrm{l}$ each of $50 \mathrm{mM}$ Tris- $\mathrm{HCl}, \mathrm{pH} 7.6$ (Tris). $50 \mu \mathrm{l} /$ well of monoclonal ascitic fluid, diluted appropriately from ( 1 in 5,000 to 1 in 10,000) with Tris to provide a detectable but inhibitable level of binding, was added to each of 54 wells of the preincubation plates. The antibody in 6 of the 54 wells on each plate was mixed with $50 \mu \mathrm{l} /$ well of Tris, to indicate maximum binding in the absence of inhibitory epitope. The antibody in all 48 test wells was mixed with $50 \mu \mathrm{l} /$ well of standard $\alpha \mathrm{l}$ (II)CB1 1B peptide, HDC, or cartilage extracts containing denatured collagen, diluted appropriately with Tris. All standards and samples were tested in duplicate wells. The plates were sealed with parafilm and incubated overnight at $37^{\circ} \mathrm{C}$ in a humidified incubator. A multichannel pipette was used to transfer $50 \mu$ l of each preincubated sample to the equivalent well of an Immulon-2 ELISA plate, coated with $2 \mu \mathrm{g} /$ well HDC and blocked with PBS-BSA as described above. It was essential to transfer all the samples from any one plate within a short space of time $(\sim 45 \mathrm{~s})$ in order to maximize accuracy. The ELISA plates were each incubated for exactly $30 \mathrm{~min}$ at room temperature and then washed three times with PBS-Tween. Second antibody and alkaline phosphatase substrate were prepared and added as described above, except that the plates were incubated with the second antibody for $2 \mathrm{~h}$. The mean absorbance from the six nonspecific binding wells was subtracted from the absorbance value of all other wells on the same plate. The percentage inhibition of binding by samples or standards was calculated relative to the mean absorbance from the six maximum binding wells on the same plate, which represented $0 \%$ inhibition ( $100 \%$ binding).

Proteolytic cleavage of native type II collagen by recombinant interstitial collagenase. Bovine native type II collagen was initially dissolved in $0.5 \mathrm{M}$ acetic acid and then diluted to a final concentration of 0.5 $\mathrm{mg} / \mathrm{ml}$ in $0.1 \mathrm{M}$ Tris- $\mathrm{HCl}, \mathrm{pH} 7.6$, containing $10 \mathrm{mM} \mathrm{CaCl}_{2}$ and recombinant human interstitial collagenase (MMP-1; kindly donated by Dr. Michael Lark, Merck, Sharpe \& Dohme, Rahway, NJ) which had been activated by incubation with $0.25 \mathrm{mM}$ aminophenyl mercuriacetate in the same buffer for $10 \mathrm{~min}$ at $37^{\circ} \mathrm{C}$. The final molar ratio of human collagenase to collagen was 1:5. The control contained type II collagen in buffer with no collagenase. The samples were incubated for $20 \mathrm{~h}$ at $30^{\circ} \mathrm{C}$ then the collagenase was inhibited by the addition of $10 \mathrm{mM}$ EDTA (final concentration). The samples were tested for immunoreactivity by immunoblotting and immunoassay.

Proteolytic cleavage of $H D C$ and $\alpha 1(I I)-C B 11 B$ peptide by clostridial collagenase. HDC and $\alpha 1$ (II)-CB11B were dissolved in Tris con- taining $5 \mathrm{mM} \mathrm{CaCl}_{2}$ and $14 \mathrm{U} / \mathrm{ml}$ chromatographically purified collagenase form III (bacterial collagenase) from Clostridium histolyticum (Advance Biofactures Corp., Lynbrook, NY). Controls contained $\mathrm{HDC}$ or $\alpha 1$ (II)-CB11 B in Tris with $5 \mathrm{mM} \mathrm{CaCl}_{2}$ but no collagenase, or collagenase in Tris with $5 \mathrm{mM} \mathrm{CaCl}_{2}$ but no HDC, nor $\alpha 1$ (II)-CB11B peptide. All the tubes were incubated overnight at $37^{\circ} \mathrm{C}$ and the collagenase was then inhibited by the addition of EDTA to a final concentration of $0.1 \mathrm{M}$. The samples were each tested for reactivity in the inhibition ELISA for denatured type II collagen.

Proteolytic cleavages of $H D C$ by $\alpha$-chymotrypsin and proteinase $K$. Aliquots of HDC at concentrations of $0.25 \mathrm{mg} / \mathrm{ml}$ or less were prepared in Tris containing $0.5 \mathrm{mg} / \mathrm{ml}$ of type VII $\alpha$-chymotrypsin or proteinase $\mathrm{K}$ (both from Sigma Chemical Co.). Control tubes contained only HDC, or $0.5 \mathrm{mg} / \mathrm{ml} \alpha$-chymotrypsin or $0.5 \mathrm{mg} / \mathrm{ml}$ proteinase $\mathrm{K}$. The samples were all incubated overnight at $37^{\circ} \mathrm{C}$ ( $\alpha$-chymotrypsin) or $56^{\circ} \mathrm{C}$ (proteinase $\mathrm{K}$ ). The $\alpha$-chymotrypsin was inactivated by addition of $115 \mu \mathrm{g} / \mathrm{ml} N$-tosyl-L-phenylalanine chloromethyl ketone (TPCK; Sigma Chemical Co.) in Tris, predissolved in ethanol (4\% $\mathrm{vol} / \mathrm{vol}$, final concentration). Proteinase $\mathrm{K}$ was inactivated by boiling for $10 \mathrm{~min}$. Degradation of the HDC by each proteinase was confirmed by SDS-PAGE (see below). The degraded collagens and control samples were each tested for reactivity in the inhibition ELISA for denatured type II collagen.

Extraction and assay of native and denatured collagen from cartilage plugs. Because $\alpha$-chymotrypsin, like all mammalian proteinases apart from interstitial collagenase, cannot cleave intact, triple helical type II collagen, this enzyme can be used to selectively degrade any collagen in cartilage which has already been denatured in situ. Conversely, cartilage can be fully solubilized by incubation with proteinase $\mathrm{K}$ at $56^{\circ} \mathrm{C}$ (its optimal temperature). Complete denaturation of the extracted collagen can then be ensured by heating. Therefore cartilage plugs were routinely extracted, first with $\alpha$-chymotrypsin and then proteinase $\mathrm{K}$. The plugs were distributed individually into Eppendorf tubes. To each tube was added $500 \mu \mathrm{l}$ of $1 \mathrm{mg} / \mathrm{ml} \alpha$-chymotrypsin in Tris containing $1 \mathrm{mM}$ iodoacetamide, $1 \mathrm{mM}$ EDTA, and $10 \mu \mathrm{g} / \mathrm{ml}$ pepstatin-A (all from Sigma Chemical Co.). The samples were incubated overnight at $37^{\circ} \mathrm{C}$. The $\alpha$-chymotrypsin was inhibited by addition of $200 \mu \mathrm{l}$ per tube of $0.4 \mathrm{mg} / \mathrm{ml} \mathrm{TPCK}$ in Tris containing $4 \%$ $\mathrm{vol} / \mathrm{vol}$ ethanol. The $\alpha$-chymotrypsin extract was separated from the residue. Each residue was then digested with $500 \mu \mathrm{l}$ of $1 \mathrm{mg} / \mathrm{ml}$ proteinase $\mathrm{K}$ in Tris containing the same protease inhibitors as described above. After digestion overnight at $56^{\circ} \mathrm{C}$, no residue remained. The proteinase $\mathrm{K}$ was inactivated and the extracted collagen fully denatured by boiling the samples for $10 \mathrm{~min}$. In order to measure any native collagen extracted by $\alpha$-chymotrypsin, a $300 \mu$ l aliquot of each $\alpha$-chymotrypsin extract was mixed with $100 \mu \mathrm{l}$ of the $1 \mathrm{mg} / \mathrm{ml}$ proteinase $\mathrm{K}$ solution and incubated and then boiled as described for cartilage residues. The TPCK-inhibited $\alpha$-chymotrypsin and boiled proteinase $\mathrm{K}$ had no inhibitory effect themselves in the inhibition ELISA.

Digestion of extracted collagen peptides with clostridial collagenase to confirm susceptibility of the extracted $C B 11 B$ epitope to cleavage by this enzyme. Collagens were extracted from plugs of $\mathrm{OA}$ cartilage with $\alpha$-chymotrypsin and proteinase $\mathrm{K}$ and the proteinases inhibited as described above. The extracts were each divided into two aliquots. To one of these was added $5 \mathrm{mM} \mathrm{CaCl}_{2}$ and $14 \mathrm{U} / \mathrm{ml}$ clostridial collagenase and to the other, $5 \mathrm{mM} \mathrm{CaCl}_{2}$ only. A control tube contained collagenase in Tris with $5 \mathrm{mM} \mathrm{CaCl}_{2}$ but no cartilage extract. All tubes were incubated overnight at $37^{\circ} \mathrm{C}$ and the collagenase activity was inhibited with EDTA as described above. The samples were all tested for reactivity in the inhibition ELISA for denatured type II collagen.

Extraction of cartilage plugs with guanidinium chloride to determine the content of non-cross-linked collagen. In one experiment, two adjacent full-depth plugs were taken from each of five OA cartilages. One of the plugs from each specimen was extracted with $\alpha$-chymotrypsin as described above. The other plug from each specimen was extracted for $72 \mathrm{~h}$ at $4^{\circ} \mathrm{C}$ with gentle rocking in $4 \mathrm{mM}$ guanidinium chloride, $0.1 \mathrm{M}$ Tris- $\mathrm{HCl}$, $\mathrm{pH} 7.3$ containing $1 \mathrm{mM}$ iodoacetamide, 1 $\mathrm{mM}$ EDTA, and $10 \mu \mathrm{g} / \mathrm{ml}$ pepstatin-A. The guanidinium chloride ex- 
tracts were dialyzed exhaustively against Tris using a membrane with a molecular weight cutoff of 3,500. A 300- $\mu$ l aliquot of each of the $\alpha$-chymotrypsin and guanidinium chloride extract was mixed with $100 \mu \mathrm{l}$ of $1 \mathrm{mg} / \mathrm{ml}$ proteinase $\mathrm{K}$, incubated overnight at $56^{\circ} \mathrm{C}$, and then boiled to inhibit the proteinase. All the extracts were tested for reactivity in the inhibition ELISA for denatured type II collagen.

Electrophoresis and immunoblotting. SDS-PAGE of purified collagens was performed using $7.5 \%$ and $10 \%, 1-\mathrm{mm}$-thick, $7-\mathrm{cm} \times 8-\mathrm{cm}$ mini-Protean gels, stained with either Coomassie Brilliant Blue or silver stain (Bio-Rad Laboratories, Mississuaga, $\mathrm{ON}$ ), as described by Dodge and Poole (11). The electrophoresed samples were transferred to a nitrocellulose membrane which was then blocked overnight at $4^{\circ} \mathrm{C}$ with PBS containing 3\% wt/ vol BSA (PBS-3\% BSA) (11). The membrane was incubated for $1 \mathrm{~h}$ at room temperature with the monoclonal antibody or control mouse ascitic fluid diluted in PBS-3\% BSA. After three washes with PBS-Tween, the membrane was incubated at $30 \mathrm{~min}$ at room temperature with the alkaline phosphatase conjugated goat anti-mouse second-step antibody described above, diluted 1 in 100 with PBS-3\% BSA. The membrane was washed well with PBS-Tween and once with distilled water. Alkaline phosphatase substrate solution was prepared from a commercial kit ( Bio-Rad) employing 5-bromo-4chloro-3-indolyl phosphate and nitroblue tetrazolium. It was added and incubated with the membrane at room temperature until optimal color had developed. Further reaction was stopped by washing off the substrate solution with distilled water.

Determination of type II collagen content based on epitope analysis. The molecular weights of the human type II collagen $\alpha 1$-chain and of peptide $\alpha 1$ (II)-CB1 1 B were each calculated from their amino acid sequences using version 1.00 of Prosis software (Hitachi Software Engineering Co. Ltd., Brisbane, CA). It was assumed that there are 99 hydroxyproline residues and 20 hydroxylysine residues for every 1,000 total residues of the $\alpha 1$ (II) chain (21). On this basis, the molecular weights of the $\alpha 1$ ( II) chain and $\alpha$ ( II)-CB1 1 B peptide were calculated as 98,291 and 2,231 respectively. Therefore, the microgram per milligram concentration of type II collagen extracted from cartilage was calculated by multiplying the concentration of extracted $\alpha 1$ (II)CB11 B by a factor of 44 .

Statistical analysis. Significance of differences in total and denatured collagen was tested using the Mann-Whitney U-test for comparison between groups and the paired $t$ test for comparison of upper 1-mm with lower 1-mm zones prepared from the same cartilage plugs.

\section{Results}

Identification of an immunogenic peptide. Five hydrophilic domains (hydrophobicity less than -1.0 ) were identified from the hydrophobicity profile of the cyanogen bromide peptide 11 of human type II collagen (Fig. 1). A 21-amino acid sequence (-Gly-Lys-Val-Gly-Pro-Ser-Gly-Ala-Hyp-Gly-Glu-Asp-GlyArg-Hyp-Gly-Pro-Hyp-Gly-Pro-Gln-) from one of these domains satisfied the four additional criteria for peptide sequence selection described above, in Methods. The peptide, $\alpha 1$ (II)CB1 1B, was synthesized with an additional amino-terminal cysteine (for conjugation) and carboxy-terminal tyrosine (for iodination if needed for an RIA), coupled to ovalbumin, and used to immunize mice.

Monoclonal antibody to $\alpha 1(I I)-C B 11 B$. Hybridoma cells from the most reactive clone were used to produce ascitic fluid containing monoclonal antibody COL2-3/4m, which was reactive with both $\alpha 1$ (II)-CB11 B and HDC. It has an $\mathrm{IgG}_{1}(\kappa)$ isotype. The specific peptide sequence recognized by the monoclonal was identified by synthesizing short, overlapping peptides from within the sequence of $\alpha 1$ (II)-CB11B and testing these for reactivity with the monoclonal (data not shown). Maximum reactivity was retained with a 13-amino acid pep-

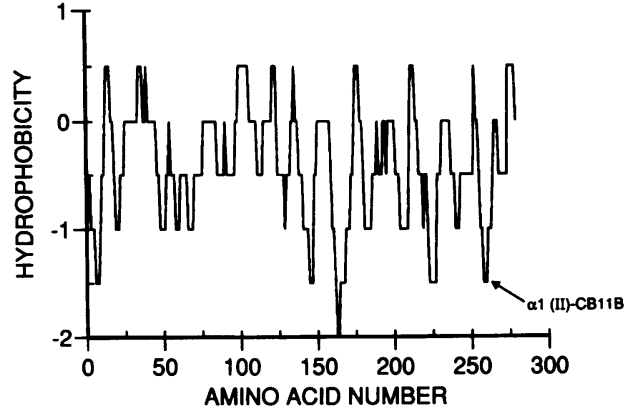

Figure 1. Hydrophobicity profile of the cyanogen bromide peptide 11 (CB11) of human type II collagen. Hydrophobicity was estimated according to the method of Hopp and Woods (15). The domain shown as " $\alpha$ l (II)-CB11B" was synthesized as a 23-amino acid peptide (see text).

tide: -Ala-Hyp-Gly-Glu-Asp-Gly-Arg-Hyp-Gly-Pro-Hyp-GlyPro-. Shortening of the sequence at the amino terminus by removing one residue reduced reactivity with $\mathrm{COL} 2-3 / 4 \mathrm{~m}$ by $70 \%$ and shortening by one residue at the carboxy terminus reduced reactivity by $33 \%$, and $92 \%$ when two residues were removed. The $\alpha 1$ (II)-CB11B peptide retained full reactivity with antibody COL2-3/4m in an inhibition assay when proline was substituted for any one of the three hydroxyproline residues (data not shown). The antibody reacted (inhibition ELISA assay) with soluble denatured type II collagen isolated from human, bovine, mouse, rat, hamster, rabbit, and horse cartilages (data not shown).

Western blotting analysis confirmed that antibody COL2$3 / 4 \mathrm{~m}$ reacts with denatured type II collagen but not with denatured collagen types I, III or X (Fig. 2). None of the collagens reacted with a control antibody, $6 \mathrm{~B}$, which has the same isotype as COL2-3/4m (see reference 22 and legend to Fig. 2). COL2$3 / 4 \mathrm{~m}$ cross-reacts with the $\alpha 3$ chain of type XI collagen, the sequence of which is identical to that of the $\alpha 1$ (II) chain, but is more heavily glycosylated $(23,24)$. It did not react with the $\alpha 1$ (XI) or $\alpha 2$ (XI) chains. The sequence of the 13-amino acid epitope of $\alpha 1$ (II)-CB11B ( see above) was compared to those of all the proteins included in release 22 of the SWISS-PROT protein sequence database, using MacMolly Tetra software (Soft Gene GmbH, Berlin, FRG). Collagen chains $\alpha 1$ (I) and $\alpha 2$ (I) each contained a sequence with 77\% homology to the 13 amino acid epitope of $\alpha 1$ (II)-CB11B, but the only protein sequences found to contain the entire epitope were those of collagen chains $\alpha 1$ (II) and $\alpha 3$ (XI). Despite the homologous sequences in the type I collagen $\alpha$-chains, antibody COL2-3/4m does not recognize denatured type I collagen, as shown by immunoblotting (Fig. 2) and immunoassay (see below and Table III).

Characteristics of the $\alpha 1(I I)-C B 11 B$ inhibition ELISA. One sample of HDC was assayed for $\alpha 1$ (II)-CB11B 15 times on each of 10 ELISA plates. From this data, the mean coefficient of variation was calculated as $9 \%$ for intraassay analysis and $10 \%$ for interassay analysis.

Typical standard curves, plotted as $\log \%$ inhibition against $\log \alpha 1$ (II)-CB11B and HDC concentrations $(\mu \mathrm{g} / \mathrm{ml})$, are shown in Fig. $3 A$. The inhibition profiles for HDC and $\alpha 1$ (II)CB1 1 B were essentially parallel ( Fig. $3 A$ ). On a molar basis the concentration ranges of antigen producing linear inhibition were similar for $\alpha 1$ (II)-CB11B and HDC (Fig. $3 B$ ), although 
A
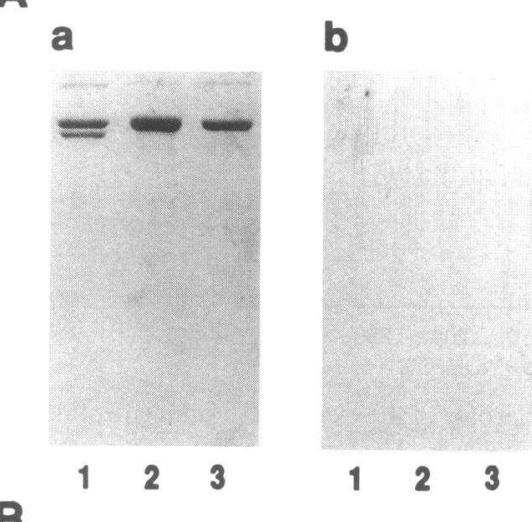

c

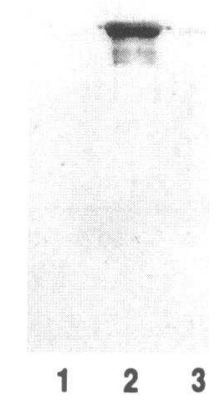

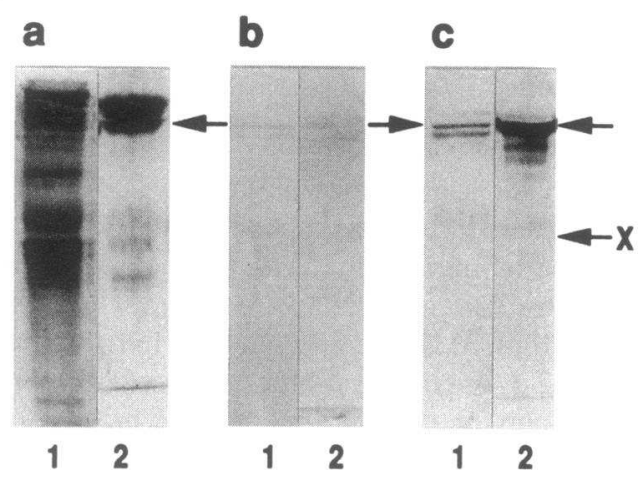

Figure 2. SDS-PAGE and Western immunoblot analysis of bovine collagens. Coomassie Brilliant Blue-stained SDS-PAGE of bovine collagens ( panel $a$ ) and Western immunoblots of the same collagens for reactivity with a control ascitic fluid containing monoclonal antibody $6 \mathrm{~B}(22)$ that has the same isotype as COL2-3/4m and reacts with unsaturated stubs of $\Delta$ di-chondroitin-4-sulfate produced by digestion of chondroitin sulfate with chondroitinase $\mathrm{ACII}$ or $\mathrm{ABC}$ (panel $b$ ) or ascitic fluid containing antibody COL2-3/4m (panel $c$ ) were performed as described in Methods. In $A$, lane $l$ is type I collagen; lane 2 is type II collagen; lane 3 is type III collagen. A $7.5 \%$ SDS-gel was used. In $B$, lane $l$ is medium enriched for type $\mathrm{X}$ collagen; lane 2 is type XI collagen. A $10 \%$ SDS-gel was used. Unlabeled arrows indicate the position of the $\alpha 3(\mathrm{XI})$ chain. Note that the medium enriched for type $\mathrm{X}$ collagen (lane 1 in $B$ ) contains small amounts of types II and XI collagen, which are detected with COL2$3 / 4 \mathrm{~m}$.

the peptide was slightly more inhibitory. Since proteinase-derived peptides were to be assayed as well as for practical convenience, the $\alpha 1$ (II)-CB11B peptide was used as a standard. Conversion to amounts of intact $\alpha 1$ (II) chains were made as described in Methods. Biological samples being assayed for denatured type II collagen were always diluted such that the level of inhibition in the assay fell within the range $20-70 \%$. This represents $0.35-3.5 \mu \mathrm{g} / \mathrm{ml} \alpha 1$ (II)-CB1 1 B $(15.4-154 \mu \mathrm{g} / \mathrm{ml}$ denatured type II collagen) in the diluted sample.

The traditional method of estimating collagen concentrations is on the basis of hydroxyproline dontent. Therefore a comparison was made of the concentrations of $\alpha 1$ (II)-CB 11 B and hydroxyproline in different HDC sumples. There was a good correlation between the two methods (Fig. 4).

It was important to demonstrate that the inhibition ELISA was specific for denatured type II collagen. Accordingly, bovine type II collagen was prepared at various concentrations in the native and heat-denatured forms and assayed for $\alpha 1$ (II)-

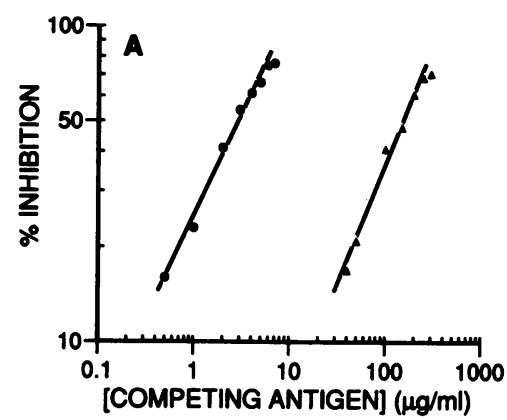

Figure 3. Standard curves for the $\alpha 1$ (II)CB11B ELISA. $\alpha 1$ (II)CB1 $1 B$ peptide and HDC were prepared at various concentrations and assayed for $\alpha 1$ (II)$\mathrm{CB} 11 \mathrm{~B}$ as described in Methods. A typical $\alpha 1$ (II)-CB11B standard curve $(\bullet)$ and the equivalent HDC dilution curve $(\Delta)$ are shown plotted as microgram per milliliter $(A)$ and micromolar $(B)$ concentrations of each antigen.

CB11B. Table II shows that only background levels of denatured $\alpha$ chain, measured as $\alpha 1$ (II)-CB11 B could be detected in the native type II collagen preparation. The $\alpha 1$ (II)-CB1 1 B epitope could not be detected by immunoassay in samples of heat denatured types I or III collagen (Table III), confirming the finding from Western blotting that $\mathrm{COL} 2-3 / 4 \mathrm{~m}$ does not react with these molecules (see above).

Denaturation of type II collagen after cleavage by interstitial collagenase. Cleavage of purified native type II collagen by recombinant human interstitial collagenase produced the characteristic three-quarter and one-quarter products, seen by SDSPAGE, but only the three-quarter product was detected by immunoblotting with COL2-3/4m (Fig. $5 \mathrm{~A}$ ). When the collagenase-cleaved collagen was assayed for $\alpha 1$ (II)-CB11B, it was found that $56 \%$ of the collagen had been denatured compared to just $11 \%$ denaturation in the native collagen control which had been incubated under the same conditions but without collagenase. The partial denaturation of the control collagen was due to the prolonged incubation $(20 \mathrm{~h})$ at $30^{\circ} \mathrm{C}$. There was no evidence to indicate that the $\alpha 1$ (II)-CB11B epitope is cleaved by interstitial collagenase.

Location of $\alpha 1$ (II)-CB11B on cyanogen bromide peptide $C B 11$. In that the $\alpha 1$ (II)-CB11B epitope amino acid sequence only occurs in the CB11 peptide of type II collagen, the antibody should only recognize CB11. Cleavage of type II collagen

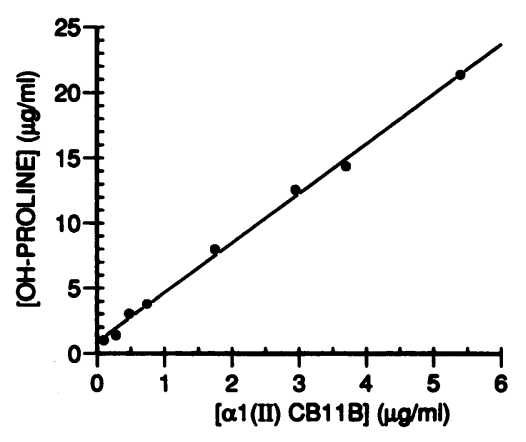

Figure 4. Correlation of $\alpha 1$ (II)-CB1 1 B content with hydroxyproline content of HDC. 
Table II. Specificity of Antibody COL2-3/4m for Denatured Rather than Native Type II Collagen

\begin{tabular}{ccc}
\hline [Collagen] & HDC & Native \\
\hline$\mu g / m l$ & & $\mu g / m l$ \\
\\
62.5 & 1.3 & \\
125 & 2.1 & 0.2 \\
250 & 5.8 & 0.0 \\
& & 0.1 \\
\hline
\end{tabular}

Values for $\alpha$ 1(II)-CB11 B by inhibition ELISA are shown.

with cyanogen bromide produced a number of peptides, including CB8, CB10, and CB11, as seen by SDS-PAGE and silver staining (Fig. $5 B$ ). The only peptide to be detected by immunoblotting with monoclonal $\mathrm{COL} 2-3 / 4 \mathrm{~m}$ was, as expected, based on the location of the epitope, CB11 (Fig. $5 B$ ).

Epitope in peptide $\alpha 1$ (II)-CBIIB is cleaved by clostridial collagenase. When clostridial collagenase alone was inhibited with $100 \mathrm{mM}$ EDTA and assayed for $\alpha 1$ (II)-CB11B it produced a small amount of inhibition, equivalent to a background level of $0.85 \mu \mathrm{g} / \mathrm{ml} \alpha 1$ (II)-CB11B (Table IV). This inhibition was probably due to cleavage of some of the HDC bound to the ELISA plate, by residual clostridial collagenase activity. HDC or $\alpha 1$ (II)-CB11B alone incubated in Tris with $\mathrm{CaCl}_{2}$ at $37^{\circ} \mathrm{C}$ for $24 \mathrm{~h}$ produced good inhibition in the assay for $\alpha 1$ (II)-CB11B, but the amount of $\alpha$ 1 (II)-CB11B detected was reduced to the background level when HDC or $\alpha 1$ (II)CB11B were treated with clostridial collagenase (Table IV), demonstrating hydrolysis of the epitope by clostridial collagenase. Therefore this property can be used to confirm the identity of the epitope in ELISA inhibition assays of samples containing it.

Proteolytic cleavage of HDC. HDC was extensively cleaved into small, undetectable peptides by both $\alpha$-chymotrypsin and proteinase $\mathrm{K}$, as judged by SDS-PAGE (data not shown) but without loss of the epitope (Table V). The inhibited enzymes themselves did not have any inhibitory activity in the assay. These results again demonstrate a small increase in immunoreactivity on cleavage of the HDC.

Total type II collagen contents and contents of denatured type II collagen in full-depth samples of human femoral condylar cartilages. The mean type II collagen concentration for the normal cartilages was $139.5 \mu \mathrm{g} / \mathrm{mg}$. Thus for normal cartilage the total type II collagen accounts for a mean (range) of $14.0 \%$ (9.2-20.8\%) of the wet weight of the tissue. For OA cartilage

Table III. Specificity of Antibody COL2-3/4m for Denatured Type II Collagen

\begin{tabular}{cccc}
\hline & \multicolumn{3}{c}{ Denatured collagen type } \\
\cline { 2 - 4 } [Collagen] & I & II & III \\
\hline$\mu g / m l$ & & $\mu g / m l$ & \\
62.5 & 0 & 1.53 & 0 \\
125 & 0 & 2.19 & 0 \\
250 & 0 & 5.34 & 0 \\
\hline
\end{tabular}

Values for $\alpha 1$ (II)-CB11B by inhibition ELISA are shown.

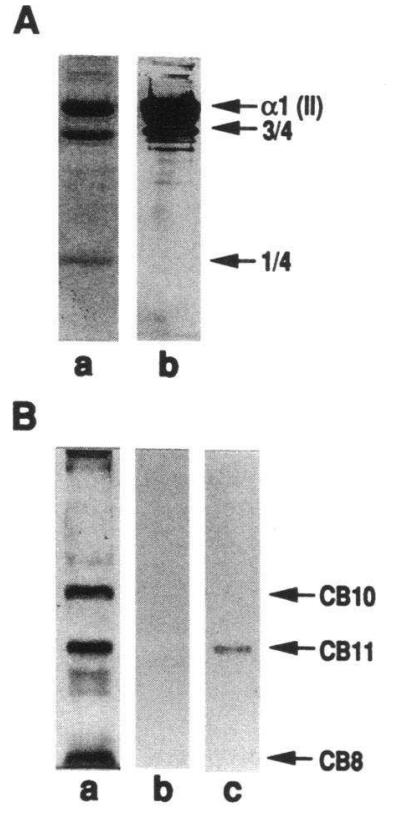

Figure 5. SDS-PAGE and Western immunoblot analysis of bovine type II collagen cleaved by human collagenase or cyanogen bromide. (A) Coomassie Brilliant Bluestained $7.5 \%$ SDS-PAGE gel (panel $a$ ) and Western immunoblot with antibody COL2-3/4m (panel $b$ ) of type II collagen after cleavage by human recombinant collagenase. Arrows indicate uncleaved $\alpha$ chain and the threequarter and one-quarter cleavage products. (B) Silver-stained $12 \%$ SDS-PAGE gel (panel $a$ ) and Western immunoblot with a control ascitic fluid (see legend to Fig. 2) (panel $b$ ) or ascitic fluid containing antibody COL2-3/4m (panel $c$ ) of cyanogen bromide peptides of type II collagen. Arrows indicate the major cyanogen bromide peptides. Staining with Coomassie or silver stain and the Western immunoblots were performed as described in Methods.

the equivalent mean (range) value was $10.3 \%$ (7.4-15.0\%). The total amount of type II collagen/mg wet weight was significantly decreased in OA compared to normal cartilage (Fig. 6).

The proportion of denatured type II collagen was signifcantly increased in OA compared to normal cartilage (Fig. 6). The mean values for the percentage of denatured collagen in normal and $O A$ cartilages were $1.1 \%$ and $6.0 \%$ respectively.

There were no correlations between either total or percent denatured type II collagen and the degree of cartilage degradation recorded as the Mankin grade of OA cartilages (Fig. 7).

Digestion of extracted collagen with clostridial collagenase. It was important to demonstrate that inhibition observed in the $\alpha 1$ (II)-CB11B ELISA by $\alpha$-chymotrypsin and proteinase K

Table IV. Clostridial Collagenase Cleaves the aI(II)-CB11B Epitope

\begin{tabular}{|c|c|c|}
\hline Sample & Treatment & $\begin{array}{l}\text { [ } \alpha \text { I(II)-CB } 1 \text { I B] by by } \\
\text { immunoassay }\end{array}$ \\
\hline & & $\mu g / m l$ \\
\hline Tris & Clostridial collagenase & 0.85 \\
\hline HDC & Tris/ $\mathrm{CaCl}_{2}$ & 3.80 \\
\hline HDC & Clostridial collagenase & 0.84 \\
\hline$\alpha 1(\mathrm{II})-\mathrm{CB} 11 \mathrm{~B}$ & Tris/CaCl ${ }_{2}$ & 4.44 \\
\hline$\alpha 1($ II)-CB11B & Clostridial collagenase & 0.83 \\
\hline
\end{tabular}

HDC and $\alpha 1$ (II)-CB 1 1 B were dissolved in Tris containing $5 \mathrm{mM}$ $\mathrm{CaCl}_{2}$ and $14 \mathrm{U} / \mathrm{ml}$ chromatographically purified clostridial collagenase. Control tubes contained HDC or $\alpha 1$ (II)-CB11B in Tris with 5 $\mathrm{mM} \mathrm{CaCl}_{2}$ but no clostridial collagenase or bacterial collagenase in Tris with $5 \mathrm{mM} \mathrm{CaCl}_{2}$ but no HDC or $\alpha 1$ (II)-CB11B. The samples were incubated overnight at $37^{\circ} \mathrm{C}$ and the clostridial collagenase was inactivated by addition of EDTA to a final concentration of $100 \mathrm{mM}$ (this concentration was required to ensure maximal inhibition of the proteinase). 
Table V. $\alpha$-Chymotrypsin and Proteinase $K$ Do Not Cleave the al(II)-CBIIB Epitope

\begin{tabular}{lc}
\hline \multicolumn{1}{c}{ Proteinase } & {$[\alpha 1(\mathrm{II})-\mathrm{CB} 11 \mathrm{~B}]$ by immunoassay } \\
\hline & $\mu \mathrm{g} / \mathrm{ml}$ \\
None & 5.0 \\
$\alpha$-Chymotrypsin & 5.7 \\
Proteinase K & 6.0 \\
\hline
\end{tabular}

Aliquots of $\mathrm{HDC}$ at $0.25 \mathrm{mg} / \mathrm{ml}$ were prepared in Tris containing 0.5 $\mathrm{mg} / \mathrm{ml}$ of type VII $\alpha$-chymotrypsin or proteinase K. Control tubes contained only HDC, or $0.5 \mathrm{mg} / \mathrm{ml} \alpha$-chymotrypsin or $0.5 \mathrm{mg} / \mathrm{ml}$ proteinase $\mathrm{K}$. The samples were incubated overnight at $37^{\circ} \mathrm{C}(\alpha$-chymotrypsin) or $56^{\circ} \mathrm{C}$ (proteinase K). The $\alpha$-chymotrypsin was inactivated by addition of $115 \mu \mathrm{g} / \mathrm{ml}$ TPCK. Proteinase $\mathrm{K}$ was inactivated by boiling for $10 \mathrm{~min}$.

extracts of human cartilage was due entirely to the $\alpha 1$ (II)CB11B epitope. Since the epitope is destroyed by treatment with clostridial collagenase (see above and Table IV), some extracts were treated with this enzyme as a control for specificity. There was a loss of immunoreactivity in each case (Table VI), demonstrating the specificity of the assay for the $\alpha 1$ (II)CB11B epitope in the cartilage extracts.

Variation in total and denatured type II collagen with depth of cartilage. From cartilage in which specimens could be obtained (minimum thickness, $2 \mathrm{~mm}$ ), plugs were divided into the upper $1 \mathrm{~mm}$ (articular zone) and lower $1 \mathrm{~mm}$ (deeper zone; these are approximate thicknesses) using a scalpel and a specially constructed slicing bed. The total type II collagen concentration was higher in the deeper (lower $1 \mathrm{~mm}$ ) compared to more superficial (upper $1 \mathrm{~mm}$ ) cartilage for four of five normal and five of eight OA specimens (Figs. 8, $A$ and $C$ ). The percentage of denatured collagen did not vary significantly with depth in normal cartilage (Fig. $8 \mathrm{~B}$ ). In one sample there was a high level of denatured collagen in the more superficial cartilage and increased denaturation in the deeper cartilage too. In two of the four other specimens, denaturation was enhanced in the more superficial cartilage, otherwise it was similar in each zone or higher in the deeper cartilage. For OA cartilage the percentage
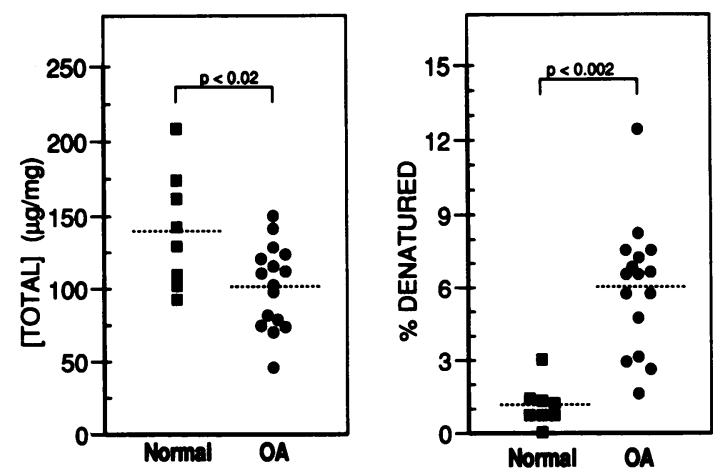

Figure 6. Total and denatured type II collagen in human femoral condylar cartilage from different patient groups. Each point is the result for cartilage obtained from one patient. Total collagen is shown as micrograms per milligram wet weight and denatured collagen is expressed as a percentage of total collagen in each specimen. Bars indicate the mean value for each patient group. Statistical analysis is by Mann-Whitney U-test. of denatured collagen was significantly higher in the upper 1mm zone (Fig. $8 \mathrm{D}$ ). This difference was seen in six of eight specimens. Of the other two specimens one showed the opposite trend and the other exhibited similar denaturation in the upper and lower levels. There was no correlation between total or percent denatured collagen in either the upper or lower zones and Mankin grade of the full-depth cartilage for normal and OA specimens (data not shown). The mean values of total and denatured collagen in the upper and lower 1-mm zones are shown in Table VII, for comparison of each zone in OA with the same zone in normal cartilage. In OA, total collagen content was only significantly reduced in the deeper cartilage of OA compared to normal. Similarly, type II collagen denaturation was only significantly increased in the lower zone of OA compared to normal cartilage. The differences in the percentage of denatured collagen in either region were not as marked as the changes seen in full-depth plugs. However it should be noted that for the depth-study, cartilage was taken from the thickest region of OA tissue and this may have been less degraded than cartilage from the thinner tissue sites.

Guanidinium chloride extracts of $O A$ cartilage. In order to determine if the type II collagen extracted from cartilage by $\alpha$-chymotrypsin was mostly derived from fibril-associated, cross-linked collagen or from nonfibrilar, non-cross-linked $\alpha$ chains, a comparison was made of extraction by $\alpha$-chymotrypsin and $4 \mathrm{M}$ guanidinium chloride. The latter is a chaotropic reagent which can only extract the nonfibrilar, non-crosslinked collagen molecules. Adjacent plugs of cartilage from five OA patients were extracted with $\alpha$-chymotrypsin or guanidinium chloride. Far less type II collagen was extracted with $4 \mathrm{M}$ guanidinium chloride than with $\alpha$-chymotrypsin. For the five OA specimens examined the mean $\pm S D$ total (native + denatured) type II collagen extracted by guanidinium chloride and $\alpha$-chymotrypsin was $0.019 \pm 0.003$ and $0.164 \pm 0.012 \mu \mathrm{g} / \mathrm{mg}$ wet weight, respectively. Therefore the amount of type II collagen extracted by $4 \mathrm{M}$ guanidinium chloride is $11.6 \%$ of that extracted by $\alpha$-chymotrypsin, suggesting that most of the denatured material extracted with $\alpha$-chymotrypsin is derived from cross-linked fibrils rather than a pool of newly synthesized, non-cross-linked $\alpha$ chains or peptides thereof. Of the type II collagen extracted with guanidinium chloride or $\alpha$-chymotrypsin, only a small proportion ( $10.5 \%$ and $7.3 \%$, respectively) was native collagen (detected after digestion with protienase $\mathrm{K})$. However, we have found that incubation of purified native type II collagen for $72 \mathrm{~h}$ at $4^{\circ} \mathrm{C}$ in $4 \mathrm{M}$ guanidinium chloride, followed by dialysis into Tris, causes over $90 \%$ of the collagen to denature, as judged by assaying for $\alpha$ ( (II)-CB1 1B (data not shown). Therefore, it is likely that most of the $\alpha 1$ (II)-CB11B extracted with guanidinium chloride is contained within newly synthesized molecules that are denatured by the extraction procedure.

Of the collagen extracted with $\alpha$-chymotrypsin, the amount of native type II collagen was too small to be detected by immunoblotting of $\alpha$-chymotrypsin extracts (Fig. 9). Moreover, peptides bearing the epitope recognized by antibody COL $2-3 / 4 \mathrm{~m}$ were too small to detect under the conditions of electrophoresis.

\section{Discussion}

The degeneration of cartilage, which is an integral feature of both OA and RA, involves localized loss of the proteoglycan 

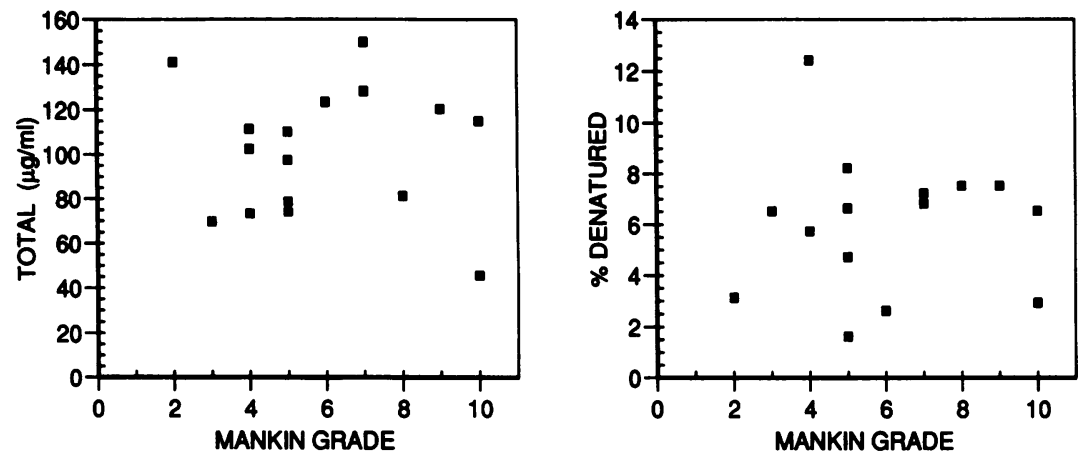

Figure 7. Lack of any correlation between Mankin grade and total or denatured type II collagen in OA cartilage. Total collagen is shown as micrograms per milligram wet weight and denatured collagen is expressed as a percentage of total collagen in each specimen.

aggrecan, its degradation $(5,6)$ and eventual loss of function of this tissue (25-27). The tissue is composed of a fibrillar organization of type II collagen (3) which endows cartilage with its tensile strength $(1,2)$. With increasing age there is a progressive reduction of the tensile properties of femoral head cartilage (28). This is not observed in the talus of the ankle joint where the incidence of osteoarthritis is relatively low compared to that observed in the hip or knee (28). In the present study we show that damage to type II collagen, measured as denaturation (unwinding) of the triple helix, is detectable in adult human femoral condylar cartilage and is increased in OA cartilage. This damage in $\mathrm{OA}$ is accompanied by a net reduction in the total type II collagen content. Previously, a loss of tensile properties was observed in OA cartilage, indicative of damage to type II collagen (25-27). The present studies reveal that the reduced tensile strength in part relates to damage to the triple helix of type II collagen leading to denaturation (unwinding). It also correlates with an apparent net reduction in the content of this molecule in OA cartilage, previously indicated by a reduction in total cartilage collagen content measured as hy-

Table VI. The Inhibition Observed in Cartilage Extracts Is Lost on Treatment with Clostridial Collagenase

\begin{tabular}{llcc}
\hline & & \multicolumn{2}{c}{$[\alpha 1$ (II)-CB1 IB] by immunoassay } \\
\cline { 3 - 4 } Sample & \multicolumn{1}{c}{$\begin{array}{c}\text { Proteinase } \\
\text { digestion }\end{array}$} & $\begin{array}{c}\text { Digested sample } \\
\text { treated with } \\
\text { Tris/CaCl }{ }_{2}\end{array}$ & $\begin{array}{c}\text { Digested sample } \\
\text { treated with } \\
\text { Tris/CaCl }\end{array}$ \\
& & \multicolumn{3}{c}{ collagenase } \\
Tris & None & 0.00 & 0.46 \\
OA-(i) & $\alpha$-chymotrypsin & 1.39 & 0.47 \\
OA-(ii) & $\alpha$-chymotrypsin & 3.22 & 0.45 \\
OA-(iii) & $\alpha$-chymotrypsin & 2.11 & 0.43 \\
OA-(iv) & $\alpha$-chymotrypsin & 3.53 & 0.48 \\
OA-(v) & $\alpha$-chymotrypsin & 2.86 & 0.47 \\
OA-(i) & Proteinase K & 53.4 & 0.49 \\
OA-(ii) & Proteinase K & 93.2 & 0.47 \\
OA-(iii) & Proteinase K & 82.5 & 0.47 \\
OA-(iv) & Proteinase K & 148.9 & 0.40 \\
OA-(v) & Proteinase K & 61.7 & 0.56 \\
& & & \\
\hline
\end{tabular}

OA cartilages (i-v) were extracted/digested with $\alpha$-chymotrypsin and proteinase $\mathrm{K}$. The digested samples were then treated with Tris $/ 5$ $\mathrm{mM} \mathrm{CaCl}{ }_{2}$ with or without $14 \mathrm{U} / \mathrm{ml}$ clostridial collagenase at $37^{\circ} \mathrm{C}$. Clostridial collagenase activity was inhibited with $100 \mathrm{mM}$ EDTA. The samples were assayed for $\alpha 1$ (II)-CB11B. droxyproline (10). This reduction may result from an increase in tissue hydration, caused by increased swelling of proteoglycans permitted by damage to collagen fibrils. Increases in water content in OA are well recognized (27). This decrease in collagen content is not observed in RA femoral condylar cartilage, although there is an increase in type II collagen denaturation similar to that observed in OA (A. Hollander, T. Heathfield, I. Pidoux, W. Fisher, E. Bogoch, and A. R. Poole, manuscript in preparation).

We also show that the damage to type II collagen of the femoral condylar cartilage in OA is most pronounced in the superficial and upper-mid zone (upper 1-mm slice): this is where the proteoglycan aggrecan is first lost from the matrix in OA (3). Such a difference between upper and lower zones is not observed in normal cartilage. If we compare damage to the lower zone in normal and OA cartilages we find that there is a significant increase in denaturation in $\mathrm{OA}$ and this increased lower zone damage is accompanied by a significant loss of type II collagen compared to normal cartilage. When, however, we compare damage to the upper zone in normal and OA cartilages, we find that the more pronounced collagen denaturation observed in the upper layers of OA cartilage is not significantly different from the level of denaturation in the same zone of normal cartilage. This result is probably due to the fact that denaturation in the upper zone was very variable within the normal group (one specimen in particular), which may reflect early, pre-clinical, OA-like changes in normal cartilage (see Fig. $6 \mathrm{~B}$ ). Indications from preliminary studies are that there is less denaturation in younger (skeletally mature) cartilages, suggesting that type II collagen denaturation may in part be a function of ageing. This may lead to excessive degenerative changes in some cases (A. Hollander, T. Heathfield, and A. R. Poole, unpublished observations).

These findings on sites of damage to type II collagen confirm and extend our earlier work, using an immunohistochemical approach coupled with a polyclonal rabbit antiserum to epitopes in the CB8 and CB11 peptides of type II collagen. Those studies also revealed that there is increased damage in OA cartilage, which is first observed in the upper region (11). In separate immunohistochemical studies with monoclonal antibody COL2-3/4m we confirm that denaturation in normal and OA cartilages usually starts at and close to the articular surface and progressively extends down into the cartilage with increasing Mankin grade (A. P. Hollander, I. Pidoux, R. Bourne, C. Rorabeck, and A. R. Poole, manuscript in preparation).

The mechanisms responsible for the denaturation (unwinding) of the triple helix have not been definitively identi- 

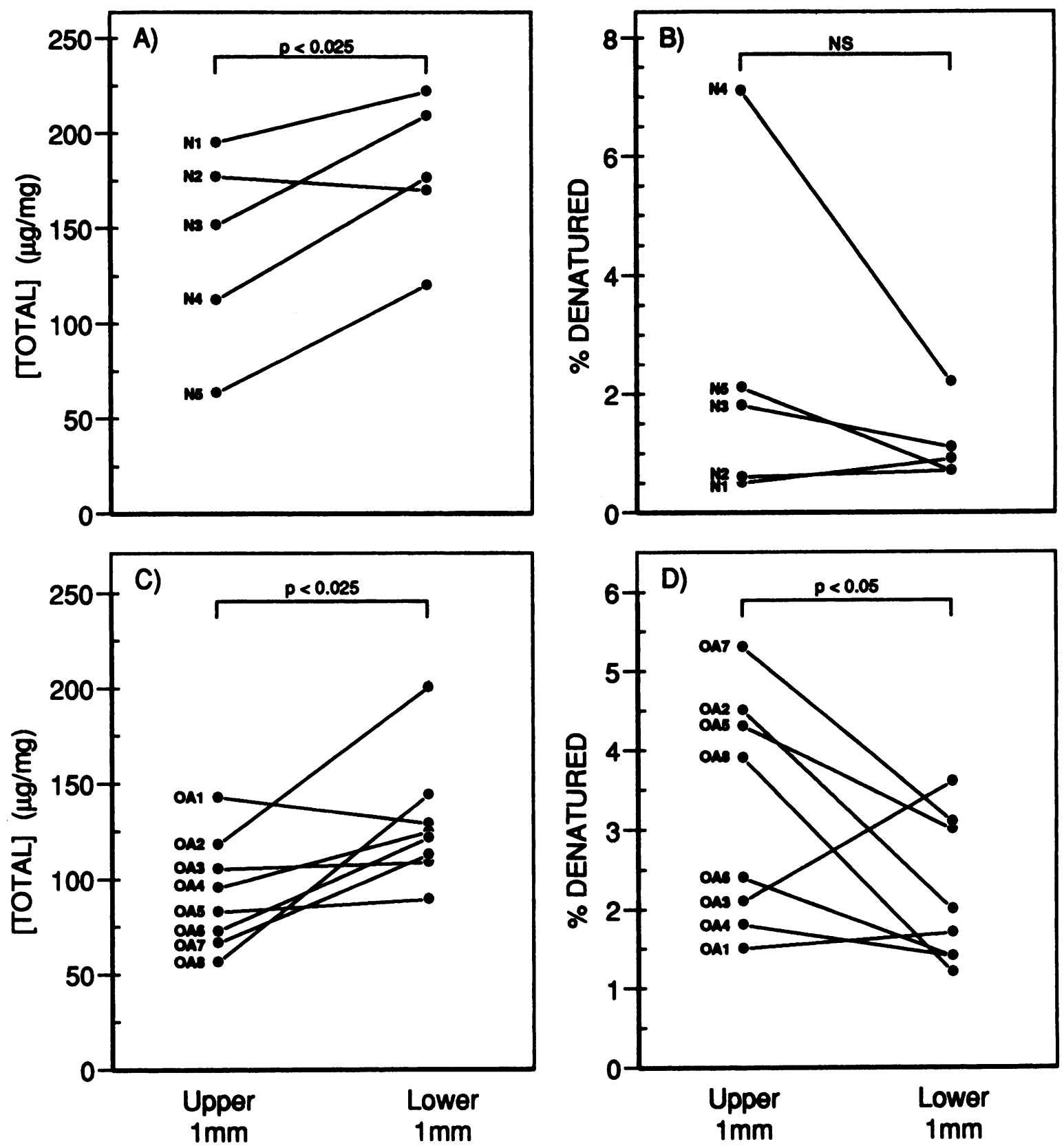

Figure 8. Variation in total and denatured type II collagen with depth in normal and OA human femoral condylar cartilage. Plugs of cartilage were divided into the more superficial zone (upper $1 \mathrm{~mm}$ ) and deeper zone (lower $1 \mathrm{~mm}$ ) using a scalpel. Each line connects upper and lower cartilages obtained from one patient. Total collagen is shown as micrograms per milligram wet weight and denatured collagen is expressed as a percentage of total collagen in each specimen. Individual patients are identified by the numbers N1-N5 for normal cartilage and OA1-OA8 for OA cartilage. A comparison of the mean values for each patient group is shown in Table VII. Statistical analysis is by Mann-Whitney U-test.

fied. These studies are currently in progress. But the only known proteinase capable of causing unwinding of the triple helix of type II collagen is interstitial collagenase (matrix metalloproteinase-1; MMP-1). This cleaves the triple helix between resudues 906 and 907 to produce the characteristic onequarter and three-quarter pieces shown here, of which our monoclonal antibody recognizes the three-quarter piece. The use of antibody COL2-3/4m will hopefully assist us in identifying any other cleavage sites within the collagen molecule that may accompany the unwinding of the triple helix. Suffice it to say that the unwinding of the triple helix is not accompanied by such rapid secondary cleavage as to remove all $\alpha$ chain frag- ments bearing the CB1 1 B epitope and render them nondetectable. Such secondary trimming can occur by proteinases such as the 72- and 92-kD gelatinases, the expressions of which are increased in OA cartilage as well as collagenase $(3,5,29)$.

The fact that most $(88.4 \%)$ of the denatured collagen extracted by $\alpha$-chymotrypsin is not extractable with $4 \mathrm{M}$ guanidinium chloride indicates that it does not represent newly synthesized collagen. Rather, it reflects denatured collagen bound to the cartilage matrix. Previously we showed that antibodies of the kind described here react primarily with denatured collagen fibrils (12). Thus based on those earlier studies, the majority of the denatured $\alpha$ chains extracted with $\alpha$-chymotrypsin most 
Table VII. Total and Denatured Collagen in Different Depths of Normal and $O A$ Cartilage

\begin{tabular}{|c|c|c|c|c|}
\hline \multirow{2}{*}{$\begin{array}{l}\text { Disease } \\
\text { group }\end{array}$} & \multicolumn{2}{|c|}{$\begin{array}{c}\text { Total type II collagen } \\
\text { Zones }\end{array}$} & \multicolumn{2}{|c|}{$\begin{array}{l}\text { Percentage of denatured } \\
\text { type II collagen } \\
\text { Zones }\end{array}$} \\
\hline & Upper & Lower & Upper & Lower \\
\hline & \multicolumn{2}{|c|}{$\mu g / m l$} & \multicolumn{2}{|c|}{$\%$} \\
\hline Normal & 139.9 & 179.5 & 2.42 & 1.12 \\
\hline OA & $92.4^{\mathrm{NS}}$ & $128.9^{*}$ & $3.2^{\mathrm{NS}}$ & $2.2^{\ddagger}$ \\
\hline
\end{tabular}

Zones are $1 \mathrm{~mm}$ thick. Values are the mean result for cartilage from five normal and eight $\mathrm{OA}$ patients. NS $=$ not significant; ${ }^{*} P<0.03$; ${ }^{\ddagger} P<0.02$ v. normal cartilage; Mann-Whitney U-test. Results for the individual patients and statistical comparisons of data for upper versus lower zones in each patients group are shown in Fig. 9.

likely reflects denaturation of type II collagen present within cross-linked fibrils, often remote from chondrocytes. If the guanidinium chloride extractable pool represents denatured, newly synthesized collagen then the amount of this which is present in the cartilage accounts for a very small proportion of the denatured collagen. Studies are in progress to examine this question further.

Until we developed this new methodology, starting with our work on the polyclonal antiserum (4), unwinding of the triple helix of type II collagen could not be detected in situ. To accurately quantitate degradation of collagen fibrils in cartilage it was necessary to develop an assay based on the use of a monoclonal antibody to a defined epitope of known location and which can be extracted intact, using selected proteinases to extract it first from nonhelical $\alpha$-chains and then from helical molecules. We identified and synthesized such an epitope located in the CB11 peptide and produced a monoclonal antibody to the synthetic peptide. The epitope is recognized in denatured but not native type II collagen $\alpha$ chains. This has made possible development of an immunoassay, used in these studies and the detection of total type II collagen. Monoclonal COL2-3/4m cross-reacts with denatured type II collagen from all mammalian species so far studied (including mouse), indi-
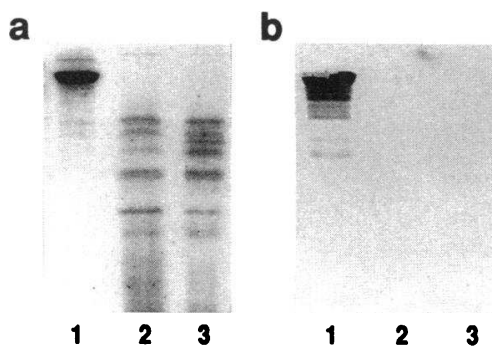

Figure 9. SDS-PAGE and Western immunoblot analysis of purified human type II collagen and $\alpha$-chymotrypsin extracts of osteoarthritic human femoral condylar cartilages. Coomassie Brilliant Blue-stained $10 \%$ SDS-PAGE gel

(panel $a$ ) and Western immunoblot with antibody COL2-3/4m (panel $b$ ) of purified human type II collagen (lane 1 ) and two osteoarthritic cartilages (lanes 2 and 3 ). Approximately $5 \mu \mathrm{g}$ of collagen II were loaded per lane, determined from epitope content by immunoassay. Note that chymotrypsin-produced peptides could be detected by Coomassie staining (panel $a$, lanes 2 and 3 ). But immunoreactive peptides were too small to be detectable on Western blotting. Also, there were no residual type II collagen $\alpha$ chains detectable after $\alpha$ chymotrypsin extraction. cating that the epitope contained within peptide $\alpha 1$ (II)CB1 1 B is highly conserved. Importantly, binding of the antibody to the collagen $\alpha$-chain is not dependent on hydroxylation of the "Y" position proline residues in the repeating Gly-X-Y triplet. This is important since it is possible that the extent of hydroxylation could change in pathological situations. Also, the epitope does not contain any potential crosslinking residues. Antibody COL2-3/4m cross-reacts with the $\alpha 3$ (XI) chain, which is considered to be the same gene product as the $\alpha 1$ (II)-chain, although it is more heavily glycosylated $(23,24)$. This cross-reactivity should not interfere with the quantitation of native or denatured type II collagen since there is only one $\alpha 3(\mathrm{XI})$-chain per molecule of type XI collagen, which represents no more than $1 \%$ of total collagen $\alpha$ chains in cartilage (30). The antibody does not cross-react with any other collagen or protein examined. Moreover, the epitope sequence is not present in any other known protein sequence.

Continuation of these studies should permit an improved understanding of the mechanisms involved in the denaturation of type II collagen in arthritis and may lead to a means of regulating this pathogenic process. Antibody COL2-3/4m will be used to detect collagen fragments released from articular cartilage in vitro and in vivo. The latter may provide a means of investigating collagen II degradation in patients with arthritis.

\section{Acknowledgments}

We thank E. de Miguel for her help with the synthesis of peptides and Mark Lepik and Jane Wishart for their artwork.

This work was supported by grants from the Shriners of North America, Medical Research Council of Canada, and Pfizer Central Research (to Dr. Poole). Dr. Hollander received a postdoctoral fellowship from the Arthritis Society of Canada.

\section{References}

1. Kempson, G. 1980. The mechanical properties of articular cartilage. In The Joints and Synovial Fluid. Volume 2. L. Sokoloff, editor. Academic Press Inc., New York. 238-239.

2. Schmidt, M. B., V. C. Mow, L. E. Chun, and D. R. Eyre. 1990. Effects of proteoglycan extraction on the tensile behaviour of articular cartilage. J. Orthop. Res. 8:353-363.

3. Poole, A. R. 1993. Cartilage in health and disease. In Arthritis and Allied Conditions: A Textbook of Rheumatology. D. J. McCarty and W. J. Koopman, editors. Lea \& Febiger, Philadelphia. 279-333.

4. Poole, A. R., J. S. Mort, and P. J. Roughley. 1993. Methods for evaluating mechanisms of cartilage breakdown. In Joint Cartilage Degradation. J. F. Woessner, Jr. and D. S. Howell, editors. Marcel Dekker, Inc., New York. 225260.

5. Poole, A. R., M. Alini, and A. P. Hollander. 1994. Cartilage degradation. In Mechanisms and Models in Rheumatoid Arthritis. B. Henderson, J. Edwards, and R. Pettipher, editors. Academic Press Ltd., London. In press.

6. Rizkalla, G., A. Reiner, E. Bogoch, and A. R. Poole. 1992. Studies of the articular cartilage proteoglycan aggrecan in health and osteoarthritis: evidence for molecular heterogeneity and extensive molecular changes in disease. J. Clin. Invest. 90:2268-2277.

7. Mitchell, N., and N. Shepard. 1978. Changes in proteoglycan and collagen in rheumatoid arthritis. J. Bone Joint Surg. 60A:349-354.

8. Harris, E. D. Jr., D. DiBona, and S. M. Krane. 1970. A mechanism for cartilage destruction in rheumatoid arthritis. Trans. Assoc. Am. Physicians. 83:267-276.

9. Kobayashi, I., and M. Ziff. 1975. Electron microscopic studies of the cartilage-pannus junction in rheumatoid arthritis. Arthritis Rheum. 18:475-483.

10. Venn, M., and A. Maroudas. 1977. Chemical composition and swelling of normal and osteoarthritic femoral head cartilage. I. Chemical composition. Ann. Rheum. Dis. 36:121-129.

11. Dodge, G. R., and A. R. Poole. 1989. Immunohistochemical detection and immunochemical analysis of type II collagen degradation in human normal, rheumatoid, and osteoarthritic articular cartilages and in explants of bovine articular cartilage cultured with interleukin-1. J. Clin. Invest. 83:647-661. 
12. Dodge, G. R., I. Pidoux, and A. R. Poole. 1991. The degradation of type II collagen in rheumatoid arthritis: an immunoelectron microscopic study. Matrix. 11:330-338.

13. Mort, J. S., G. R. Dodge, and A. R. Poole. 1993. Direct evidence for metalloproteinases mediating matrix degradation in interleukin-1 stimulated human articular cartilage. Matrix. 13:95-102.

14. Mankin, H. J., H. Dorfman, L. Lippiello, and A. Zarins. 1971. Biochemical and metabolic abnormalities in articular cartilage from osteoarthritic human hips. J. Bone Joint Surg. 53A:523-537.

15. Hopp, T. P., and K. R. Woods. 1981. Prediction of antigenic determinents from amino acid sequences. Proc. Natl. Acad. Sci. USA. 78:3824-3828.

16. Hughes, C. E., B. Caterson, R. J. White, P. J. Roughley, and J. S. Mort 1992. Monoclonal antibodies recognizing protease-generated neoepitopes from cartilage proteoglycan degradation. J. Biol. Chem. 267:16011-16014.

17. Köhler, G., and C. Milstein. 1976. Derivation of specific antibody-producing tissue culture and tumor lines by cell fusion. Eur. J. Immunol. 6:511-519.

18. Rosenberg, L. C., H. U. Choi, L.-H. Chang, T. L. Johnson, S. Pal, C. Webber, A. Reiner, and A. R. Poole. 1985. Isolation of dermatan sulfate proteoglycans from mature bovine articular cartilages. J. Biol. Chem. 260:6304-6313.

19. Epstein, E. H., Jr. 1974. (Alpha 1(3))3 human skin collagen: release by pepsin digestion and preponderance in fetal life. J. Biol. Chem. 249:3225-3231.

20. Burleigh, M. C., A. J. Barrett, and G. S. Lazarus. 1974. Cathepsin B1: a lysosomal enzyme that degrades native collagen. Biochem. J. 137:387-389.

21. Nimni, M. E. 1983. Collagen: structure, function and metabolism in normal and fibrotic tissues. Semin. Arthritis Rheum. 13:1-86.

22. Matsui, Y., M. Alini, C. Webber, and A. R. Poole. 1991. Characterization of aggregating proteoglycans from the proliferative, maturing, hypertrophic and calcifying zones of the cartilage physis (growth plate). J. Bone Joint Surg 73A:1064-1074.
23. Morris, N. P., and H. P. Bächinger. 1987. Type XI collagen is a heterotrimer with the composition $(1 \alpha 2 \alpha 3 \alpha)$ retaining non-triple-helical domains. $J$ Biol. Chem. 262:11345-11350.

24. Eyre, D. R., and J.-J. Wu. 1987. Type XI or $1 \alpha 2 \alpha 3 \alpha$ collagen. In Structure and Function of Collagen Types. R. Mayne and R. E. Burgeson, editors. Academic Press, Inc., New York. 261-281.

25. Kempson, G. E., H. Muir, C. Pollard, and M. Tuke. 1973. The tensile properties of the cartilage of human femoral condyles related to the content of collagen and glycosaminoglycans. Biochim. Biophys. Acta. 297:465-472.

26. Akizuki, S., V. C. Mow, F. Muller, J. C. Pita, and D. S. Howell. 1986. Tensile properties of human knee joint cartilage. I. Influence of ionic conditions, weight bearing and fibrillation on the tensile modulus. J. Orthop. Res. 4:379-392.

27. Mow, V., D. S. Howell, and J. A. Buckwalter. 1990. Structure-function relationships of articular cartilage and the effects of joint instability and trauma on cartilage function. In Cartilage Changes in Osteoarthritis. K. D. Brandt, editor. Indiana University School of Medicine, Ciba-Geigy Co., Summit, NJ. 22-42.

28. Kempson, G. E. 1991. Age-related changes in the tensile properties of human articular cartilage: a comparative study between the femoral head of the hip joint and the talus of the ankle joint. Biochim. Biophys. Acta. 1075:223-230.

29. Mohtai, M., R. Lane Smith, D. J. Schurman, Y. Tsuji, F. M. Torti, N. I. Hutchinson, W. G. Stetler-Stevenson, and G. I. Goldberg. 1993. Expression of 92-kD type IV collagenase/gelatinase (gelatinase B) in osteoarthritic cartilage and its induction in normal human articular cartilage by interleukin 1. J. Clin. Invest. 92:179-185

30. Eyre, D. R., J.-J. Wu, and S. Apone. 1987. A growing family of collagens in articular cartilage: Identification of 5 genetically distinct types. J. Rheumatol. 14 (Suppl.):25-27. 